\title{
COMPARISON OF STUD AND TELESCOPIC CROWN ATTACHMENTS FOR MINI-IMPLANT RETAINED MANDIBULAR COMPLETE OVERDENTURES
}

\author{
Walid Mohamed E. Ghoneim¹, Magdy M. Badawy², Diab F. El Haddad ${ }^{3}$
}

\begin{abstract}
Objectives: The objective of this study was to make a radiographic and bite force comparison between stud and double telescopic crowns using two different attachment systems for two interforaminal mini implants retaining mandibular complete overdenture. Subjects and Materials: Randomized, controlled, clinical study was done on 20 completely edentulous patients, divided into 2 equal groups. The first group (study group), patients were treated by two mini-implants (with ball abutments) of $2.4 \mathrm{~mm}$ diameters and $13 \mathrm{~mm}$ lengths (in the canine regions) retaining mandibular overdentures and by conventional maxillary complete dentures. The second group (control group), patients were treated by two mini-implants (with square head abutments) of $2.4 \mathrm{~mm}$ diameters and $13 \mathrm{~mm}$ lengths (in the canine regions) retaining mandibular overdentures and by conventional maxillary complete dentures. Results: At the end of the 12 months, a total bone loss of $0.69 \mathrm{~mm}$ for group I (with ball abutments), and $1.64 \mathrm{~mm}$ for group II (with square head abutments) was detected. For Maximum Bite Force, there was no significant difference between the two groups at all follow-up periods. Conclusion: Mandibular overdentures retained by two mini implants is considered as an acceptable treatment modality over the one-year observation period. Ball attachments are more favorable than telescopic attachments, in regard to the reduction of the peri-implant bone loss, while, the type of the attachment has less effect on the maximum bite force.
\end{abstract}

KEY WORDS: mini implants supported over denture, Ball and socket attachments, telescopic attachments, cone beam computed tomography, maximum bite force.

\section{INTRODUCTION}

Implant overdentures are considered a proper treatment option for edentulous patients as they provide better retention and stability than the conventional complete dentures. The implants can reduce the bone resorption of the alveolar ridge, besides they improve masticatory forces and psychological status of the patient ${ }^{(1,2)}$.
The primary advantages of using mini implants are low cost, ability to be placed in narrower wide ridges, almost always placed through a flapless surgical procedure which is known to decrease postsurgical discomfort and morbidity for patients, and the majority are designed as a one-piece implant with the ability to immediately load the prosthesis and provide tangible treatment benefit to the patient in a single clinical visit ${ }^{(3,4)}$.

1. Dentist at Ministry of Defense, Masters Candidate, Faculty of Dental Medicine, Boys, Cairo, Al-Azhar University.

2. Professor of Removable Prosthodontics, Faculty of Dental Medicine, Boys, Cairo, Al-Azhar University.

3. Professor of Removable Prosthodontics, Faculty of Dental Medicine, Boys, Cairo, Al-Azhar University.

- Corresponding author: walidghoneim66@gmail.com

DOI: $10.21608 /$ ajdsm.2020.47104.1124 
Although, four mini dental implants have been recommended to support the mandibular overdentures, there are several studies that reported good results of using only two or three mini dental implants to support the mandibular overdentures ${ }^{(5,6)}$. Stud attachments provide the most resilient option, permitting a vertical movement, and distribute the forces over the soft tissue and the implants. However, disadvantages include prosthesis complexity and wear caused by mastication, which ultimately result in retention loss and the need of replacement every 6 to 9 months ${ }^{(7)}$.

Non-rigid telescopes include crowns with tiny spaces between the primary and secondary copings. Telescopic crowns have an advantage of providing adequate retention, improved mastication and phonetics, they also minimize movement of the distal portions of the denture base away from the edentulous ridge and improve horizontal stability of the dentures especially in patients with advanced mandibular ridge atrophy ${ }^{(8)}$.

The conventional radiographs provide a twodimensional view of three-dimensional structures. The CBCT examination enables a three-dimensional evaluation of the structures, lower radiation dose, and the possibility of importing and exporting data, generally, the use of CBCT is widely defended in the literature due to the greater precision and the clarity of the images ${ }^{(9,10)}$.

Maximum bite force is a useful indicator of the functional state of the masticatory system and the loading of the artificial teeth. The association between maximum bite force and the amount of occlusal contact is closest in the posterior region, and as a consequence, loss of support and retention in molar area results in reduction of bite force ${ }^{(11,12)}$.

This study was to made a to evaluate the radiographic and bite force comparison between stud and double telescopic crowns using two different attachment systems for two interforaminal mini implants retaining mandibular complete overdenture.

\section{SUBJECTS AND MATERIALS}

\section{Study Population:}

Twenty completely edentulous patients were randomly selected from the Outpatient Clinic, Department of Removable Prosthodontics, Faculty of Dental Medicine, Al-Azhar University (Boys, Cairo) and Maadi military hospital.

\section{Study design:}

Randomized, controlled, clinical trial.

Inclusion criteria: Patients' age ranged between 55-65 years, the last tooth was extracted not less than 6 months before the date of surgery, adequate inter-arch space and normal ridge relationship, adequate bone width and height in the interforaminal region to accept mini-implants of $2.4 \mathrm{~mm}$ diameter and $13 \mathrm{~mm}$ length.

Exclusion criteria: Systemic diseases that might affect healing, complicate surgical procedures, or contribute to bone resorption as uncontrolled diabetes, mental disability, unco-operative patients, heavy smokers, History of head and neck radiotherapy or chemotherapy.

The Patients were classified randomly in two equal groups: The first group (ten patients): patients of this group were treated by two mini-implants (with ball abutments) of $2.4 \mathrm{~mm}$ diameters and $13 \mathrm{~mm}$ lengths (in the canine regions) retaining mandibular overdentures and by conventional maxillary complete dentures, The second group (ten patients): patients of this group were treated by two mini-implants (with square head abutments) of $2.4 \mathrm{~mm}$ diameters and $13 \mathrm{~mm}$ lengths (in the canine regions) retaining mandibular overdentures and by conventional maxillary complete dentures.

Pre-operative evaluation should be done in several ways including patient history that cover medical and dental history to exclude systemic and local conditions that affect bone resorption. Extraoral and intra-oral examinations were performed for each patient to detect any facial abnormalities, abnormal bony protuberances, undercuts, and irregularities. Diagnostic casts were mounted on a 
mean value articulator to examine adequate interarch space and the space available for the lower denture. Cone beam computed tomography (CBCT) was used for the radiographic examination using radiographic stent to detect the presence of any pathological lesions, determine bone quality at the regions that was planned for the implant insertion, determine the available bucco-lingual width of the bone on the cross-sectional views, and to determine the available bone height. After evaluations were performed, new complete maxillary and mandibular dentures were constructed by the conventional method.

\section{Insertion of the implants:}

Mini dental implants of $2.4 \mathrm{~mm}$ diameters and $13 \mathrm{~mm}$ lengths were used withe ball head for group I and square head for group II (MDI Mini Dental Implant, 3MESPE, USA).

The used tools of the surgical kit was $1.1 \mathrm{~mm}$ pilot drill, $1.7 \mathrm{~mm}$ surgical drill, winged thumb wrench, graduated torque wrench with its adapter, and long ratchet adapter.

Flapless technique was used to insert the implants, the surgical stent was used to make an initial penetration through the cortex of the bone using $1.1 \mathrm{~mm}$ pilot, the stent then removed and the drilling then continued by the $1.1 \mathrm{~mm}$ pilot drill, the $1.7 \mathrm{~mm}$ surgical drill then used to widen the osteotomy site to about only two third of the length of the drill to give adequate initial stability. The initial $1.1 \mathrm{~mm}$ pilot drill was used as a paralleling pin which placed in the first osteotomy site to act as a guide for the other implant site drilling.

The implant was carried to the osteotomy site using the vial cap that is attached to it and the first turns were done with the vial cap until resistance was met, then, the winged thumb wrench was attached to the implant and rotated clockwise while exerting downward pressure until resistance was encountered.

The graduated torque wrench was used to finalize the insertion in which the ideal implant position allows the abutment head to protrude from the gingival soft tissue at its full length but with no neck or thread portions visible. After inserting the implant to it full length, the resistance torque should be at least $35 \mathrm{NCM}$ to allow immediate loading of the implants, Fig. (1).

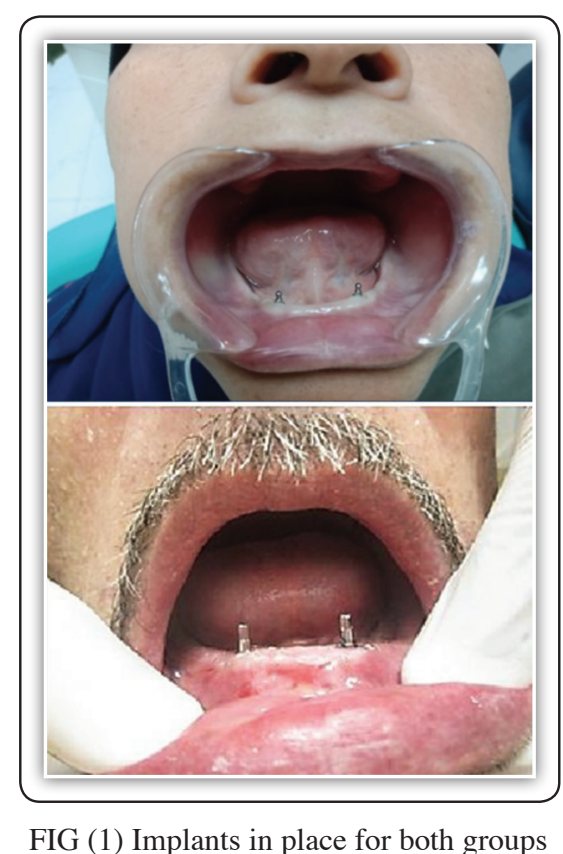

\section{Impression making for telescopic coping con- struction:}

Impression posts placed over the abutments of the square head type implants and a suitable stock tray selected for making the impression by closed tray technique in which rubber base impression material used, then, after setting, and the implant analogues connected to the impression posts, the impression then material poured in stone and the casts sent to the lab for the fabrication of the telescopic coping.

\section{The Laboratory work for the fabrication of the telescopic coping:}

Wax pattern copings fabricated for the first crowns over the abutments of the implant analogues according to the resilient design which is cylindrical with tapered walls, then these patterns casted, the Second crowns (telescopic crowns) then fabricated over the first with considering a small space between them to give adequate resiliency, and making means of retention on the outer surface of the second 
crown to be retained easily in the fitting surface of the denture.

\section{Loading of the implants:}

The implants were loaded immediately after insertion of the implants for both groups in which the positions of the abutments of the implants marked by alginate impression material in the fitting surface of the lower denture then relieved using an acrylic bur so that, the relieved areas could accommodate the abutments of both groups.

For the first group, the ball attachment sockets connected to the ball abutments, an elastomeric shim used to block out any undercut, Self-cured acrylic resin then inserted in the relieved areas, and the denture was fully seated in its place in which the patient then asked to bite in centric maximum intercuspation. After setting, the denture removed, any excess material was trimmed.

For the second group patients, Zinc-Oxide eugenol cement used to cement the first crowns to the abutments. After the cement has partially set, the second crowns connected to the first crowns, the undercuts blocked out using putty rubber base impression material, Self-cured acrylic resin used to pick-up second crowns as for first group, Fig (2).

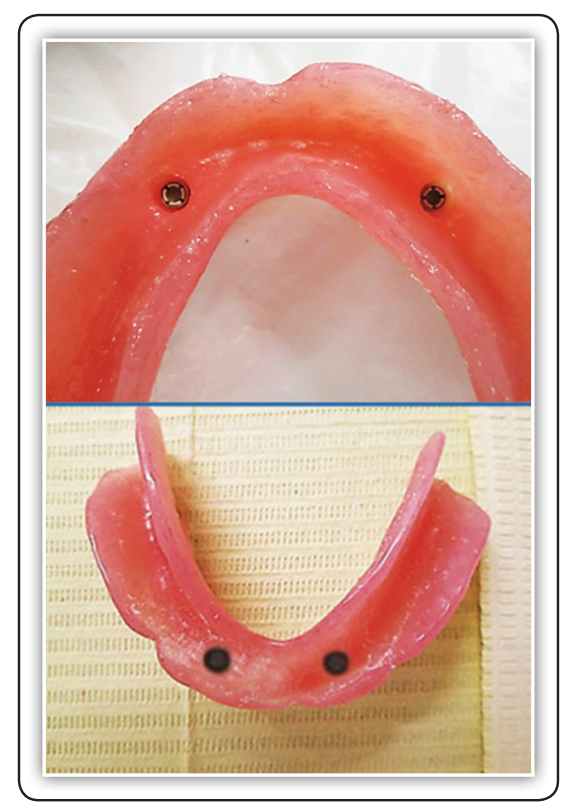

FIG (2) Ball and socket attachments for first group and second crowns for second group picked up in the fitting surface of lower dentures

\section{Patient evaluation:}

The patients were frequently recalled for the clinical evaluation, the clinically successful osseointegration was evaluated throughout the study period. The linear measurements were done using Anatomage InVivoDental viewer software supplied with the CBCT radiographs, in the coronal plane, the marginal bone was evaluated mesially and distally around the implants, in the sagittal plane, the marginal bone was evaluated buccally and lingually around the implants. This was done by drawing a horizontal line passing through the apex of the implant, then, vertical lines were drawn from the crest of the ridge next to the implant to the horizontal line passing through the apex of the implant, the software automatically given the values of the vertical lines in millimeter.

Maximum bite force (MBF) measured at the molar/premolar areas in right and left sides by using a portable occlusal force gauge which composed of a gauge for hydraulic pressure and a bite elements which consist of vinyl materials enclosed within tube from polyethylene. Bite force measured for all patients of both groups at zero, six, and twelve months follow-up periods. During testing, the patient seated in an upright position. For each patient, the mean of at least 10 records of the right and left sides collected.

\section{Statistical analysis:}

Numerical data were presented as mean and standard deviation (SD) values. Intergroup comparisons were done using independent t-test, intragroup comparison of bone height and biting force within each group done utilizing repeated measures ANOVA, and intragroup comparison of bone height difference (bone loss) during the two follow-up intervals (from base line to 6 months, and from 6 to 12 months) done utilizing paired samples t-test. The significance level was set at $\mathrm{p} \leq 0.05$ for all tests. Statistical analysis was performed with IBM SPSS Statistics Version 26 for Windows. 


\section{RESULTS}

\section{Bone resorption:}

When bone height measured at each followup period for both groups, it was found that the highest value was at baseline $(12.63 \pm 0.11$, $12.60 \pm 0.09)$, followed by 6 months $(12.02 \pm 0.10$, $11.51 \pm 0.12$ ), while the lowest value was found at 12 months $(11.89 \pm 0.12,10.93 \pm 0.14)$ for group I, and II respectively, the difference was statistically significant. It was found that the bone loss occurred from base line to 6 months was $(0.60 \pm 0.03$, $1.09 \pm 0.05)$, and that occurred from baseline to 12 months was $(0.13 \pm 0.03,0.59 \pm 0.10)$ for group $\mathrm{I}$, and II respectively, the difference was statistically significant. After 12 months it was found a total bone loss of $(0.69 \pm 0.05)$ for group I, and $(1.64 \pm 0.09)$ for group II, Tab. (1) and Fig. (3). This amount of bone loss was within the accepted range that occurs within the first year, and the difference was statistically significant.

TABLE (1) Mean, Standard deviation (SD) values of the amount of bone loss in (mm) for both groups

\begin{tabular}{|c|c|c|c|c|}
\hline \multirow{2}{*}{ Site } & \multirow{2}{*}{ Follow-up } & \multicolumn{2}{|c|}{ Groups (mean \pm SD) } & \multirow{2}{*}{$\mathrm{p}$-value } \\
\hline & & Group (I) & Group (II) & \\
\hline \multirow{3}{*}{ Buccal } & Baseline-6 months & $0.55 \pm 0.10$ & $1.05 \pm 0.11$ & $<0.001 *$ \\
\hline & 6-12 months & $0.14 \pm 0.09$ & $0.60 \pm 0.12$ & $<0.001 *$ \\
\hline & Baseline- 12 months & $0.69 \pm 0.15$ & $1.64 \pm 0.12$ & $<0.001 *$ \\
\hline \multirow{3}{*}{ Lingual } & Baseline-6 months & $0.60 \pm 0.01$ & $1.06 \pm 0.12$ & $<0.001 *$ \\
\hline & 6-12 months & $0.14 \pm 0.04$ & $0.57 \pm 0.12$ & $<0.001 *$ \\
\hline & Baseline- 12 months & $0.74 \pm 0.04$ & $1.64 \pm 0.17$ & $<0.001 *$ \\
\hline \multirow{3}{*}{ Mesial } & Baseline- 6 months & $0.69 \pm 0.02$ & $1.08 \pm 0.14$ & $<0.001 *$ \\
\hline & 6-12 months & $0.11 \pm 0.06$ & $0.62 \pm 0.11$ & $<0.001 *$ \\
\hline & Baseline- 12 months & $0.80 \pm 0.06$ & $1.70 \pm 0.18$ & $<0.001 *$ \\
\hline \multirow{3}{*}{ Distal } & Baseline- 6 months & $0.57 \pm 0.06$ & $1.15 \pm 0.11$ & $<0.001 *$ \\
\hline & 6-12 months & $0.14 \pm 0.06$ & $0.55 \pm 0.17$ & $<0.001 *$ \\
\hline & Baseline- 12 months & $0.71 \pm 0.11$ & $1.70 \pm 0.20$ & $<0.001 *$ \\
\hline \multirow{3}{*}{ Average } & Baseline-6 months & $0.60 \pm 0.03$ & $1.09 \pm 0.05$ & $<0.001 *$ \\
\hline & 6-12 months & $0.13 \pm 0.03$ & $0.59 \pm 0.10$ & $<0.001 *$ \\
\hline & Baseline- 12 months & $0.69 \pm 0.05$ & $1.64 \pm 0.09$ & $<0.001 *$ \\
\hline
\end{tabular}

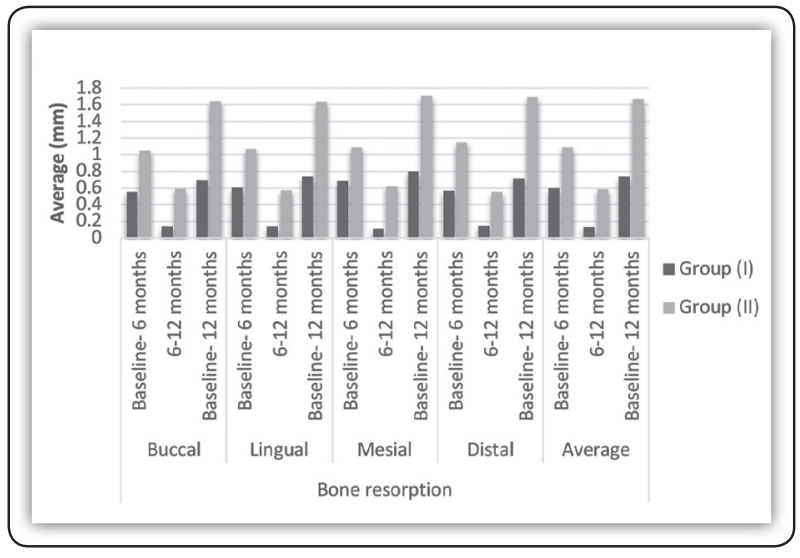

FIG (3) Bar chart showing average values of bone height difference $(\mathrm{mm})$ in different groups

\section{Biting force:}

Although, there was a significant difference between values measured at different followup periods for both groups in which the highest values were found after 12 months $(184.55 \pm 6.53$, $184.50 \pm 7.33)$, followed by 6 months $(183.25 \pm 5.60$, $183.55 \pm 7.12$ ), while the lowest values were found at baseline $(143.55 \pm 6.35,141.85 \pm 8.39)$ for group I, and II respectively, there was no significant different between both groups at all follow-up periods, Tab. (2) and Fig. (4). 
TABLE (2) Mean, Standard deviation (SD) values of biting force in newton $(\mathrm{N})$ for both groups

\begin{tabular}{|c|c|c|c|}
\hline \multirow{2}{*}{ Follow-up } & \multicolumn{2}{|c|}{ Groups (mean \pm SD) } & \multirow{2}{*}{ p-value } \\
\cline { 2 - 3 } & Group (I) & Group (II) & \\
\hline Baseline & $143.55 \pm 6.35$ & $141.85 \pm 8.39$ & $0.616 \mathrm{~ns}$ \\
\hline 6 months & $183.25 \pm 5.60$ & $183.55 \pm 7.12$ & $0.918 \mathrm{~ns}$ \\
\hline 12 months & $184.55 \pm 6.53$ & $184.50 \pm 7.33$ & $0.987 \mathrm{~ns}$ \\
\hline
\end{tabular}

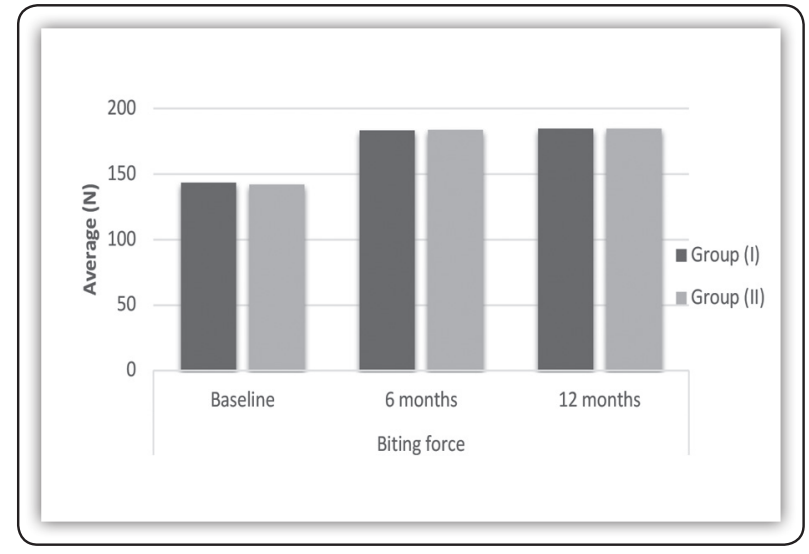

FIG (4) Bar chart showing average values of biting force $(\mathrm{N})$ in different groups

\section{DISCUSSION}

\section{Discussion of the methodology:}

In this study, mandibular implant overdentures were constructed opposing conventional maxillary dentures as most problems occur with the mandibular conventional dentures; because of the resorption of the bone, also the movement of the tongue, cheeks, and lips ${ }^{(13)}$.

Recently, it was found that, the patients with mandibular implant supported overdentures are more likely to positively modify their diet than patients with conventional dentures, the overall Patient satisfaction increases with an implantretained overdenture when compared to a complete denture ${ }^{(14)}$.
The conventional diagnostic aids such as diagnostic casts, periapical, and panoramic radiographs cannot determine the three-dimensional (3D) position of the implant, so, the radiographic examination was performed using a dual purpose (diagnostic as well as surgical) stent in conjunction with a CBCT scan imaging ${ }^{(15)}$.

The mini dental implants are considered to be a good alternative to the standard dental implants due to their small diameters, low costs, and avoidance of additional surgical procedures such as bone augmentation. Patients reported a significant improvement in the quality of life, overdenture stability and comfort, speaking, and chewing ability following the rehabilitation by these implants ${ }^{(16)}$.

In this study, only two mini implants used to support the mandibular overdentures. Das et al ${ }^{(17)}$. concluded that the two-implant overdentures can be considered as the first choice standard of care for the edentulous patients. Jofre et al ${ }^{(18)}$. reported that, although four mini-implants have been recommended as an alternative treatment for the edentulous patients, no published evidence indicated that this option is better than the use of two. The telescopic copings for group II were fabricated according to the resilient design, to allow a slight movement of the overdenture to avoid stresses on the implants ${ }^{(19)}$.

The implants were loaded immediately after insertion of the implants for both groups. Immediate loading has the advantage of the reduction of the treatment time. Several investigations reported high success rate of immediate loading of mini implants which is comparable to the conventional delayed loading ${ }^{(20)}$.

Many researchers determined the bite force by measuring the maximum bite force (MBF), which was assessed unilaterally using Occlusal Force Meter (GM-10, Nagano Keiki, Tokyo, Japan). To assess MBF, the force transducer was positioned on the occlusal surface of the first molar/premolar 
area. Subjects were seated upright in a dental chair and were trained before the actual test to create confidence. The mean value out of 10 tests, with a one-minute rest between tests, represented the MBF for each side ${ }^{(12,21)}$.

A possible cause of the change in bone height may be related to the stresses acting on the periimplant bone, also, this bone height change could be explained as a response to the surgical trauma that included osteotomy to insert the implants, bone height change could be a part of bone remodeling around the dental implants following wound healing after the implant placement, also it could be due to the remodeling as a response to the functional stresses after insertion of the prosthesis ${ }^{(22)}$.

These results were in accordance with several studies; Tuzzoloet al ${ }^{(23)}$.concluded that the use of the mini implants appears to be predictable. Sohrabiet al ${ }^{(24)}$.reported a high success rate of the mini implants and concluded that these implants are a good solution for specific clinical situations.

When a comparison between the groups at the end of the year was done, it was found that bone loss around the implants for group II was greater than that for group I, and this difference in the bone height change was statistically significant; this could be explained by the more resiliency of the silicon cap that found in the ball attachment in group I which provide the most resilient option, permitting a vertical movement, and distribute the forces over the soft tissue and the bone ${ }^{(25,26)}$.

When values of biting force compared at different follow-up times between both groups, there was no significant difference in these values, this can be explained by the less effect of the attachment type on the level of the biting force as explained in several studies. When values of biting force compared at different follow-up times within each group, There was a significant difference between these values, the highest value was found after 12 months, followed by 6 months, while the lowest value was found at baseline, these results can be explained by the more confidence and adaptation that the patient can gain while using the overdenture along the follow-up period ${ }^{(27,28)}$.

\section{CONCLUSIONS}

Within the limitations of this study, it could be concluded that:

- Mandibular overdentures retained by two mini implants either with ball and socket abutments or telescopic abutments considered an acceptable treatment modality over the oneyear observation period.

- Using ball attachments to retain two mini implants retained mandibular overdentures are more favorable than telescopic attachments, in regard to the reduction of the peri-implant bone loss.

- The type of the attachment used has less effect on the maximum bite force.

\section{REFERENCES}

1. Huang JZ, Lin XF. [Evaluation of the clinical efficacy of implant-supported overdenture with edentulous mandible in elderly patients]. Hua Xi Kou Qiang Yi Xue Za Zhi. 2019;37(4):428-32.

2. Bakker MH, Vissink A, Meijer HJA, Raghoebar GM, Visser A. Mandibular implant-supported overdentures in (frail) elderly: A prospective study with 20-year follow-up. Clin Implant Dent Relat Res. 2019;21(4):586-92.

3. MA EL, Abdraboh AE, Aboelnagga MM, Ghali RM, Lebshtien IT. Effect of Low-Level Laser Irradiation on Stability and Marginal Bone of Narrow Implants Retaining Overdentures in Moderately Controlled Diabetic Patients. J Oral Implantol. 2019;45(5):391-7.

4. Zygogiannis K, Aartman IH, Parsa A, Tahmaseb A, Wismeijer D. Implant Mandibular Overdentures Retained by Immediately Loaded Implants: A 1-Year Randomized Trial Comparing the Clinical and Radiographic Outcomes Between Mini Dental Implants and Standard-Sized Implants. Int J Oral Maxillofac Implants. 2017;32(6):1377-88.

5. El-Sheikh AM, Shihabuddin OF, Ghoraba SM. Two versus three narrow-diameter implants with locator attachments 
supporting mandibular overdentures: a two-year prospective study. Int J Dent. 2012;2012:285684.

6. Warin P, Rungsiyakull P, Rungsiyakull C, Khongkhunthian P. Effects of different numbers of mini-dental implants on alveolar ridge strain distribution under mandibular implant-retained overdentures. J Prosthodont Res. 2018;62(1):35-43.

7. Ortensi L, Martinolli M, Borromeo C, Ceruso FM, Gargari M, Xhanari E, et al. Effectiveness of Ball Attachment Systems in Implant Retained- and Supported-Overdentures: A Three- to Five-Year Retrospective Examination. Dent J (Basel). 2019;7(3).

8. Awaad NM, Eladl NM, Abbass NA. Assessments of Bone Height Loss in Telescopic Mandibular Implant-Retained Overdentures Retained by Two and Four End - Osseous Implants: A Randomized Clinical Trial. Open Access Maced J Med Sci. 2019;7(4):623-37.

9. Bornstein MM, Horner K, Jacobs R. Use of cone beam computed tomography in implant dentistry: current concepts, indications and limitations for clinical practice and research. Periodontol 2000. 2017;73(1):51-72.

10. Shokri A, Jamalpour MR, Khavid A, Mohseni Z, Sadeghi M. Effect of exposure parameters of cone beam computed tomography on metal artifact reduction around the dental implants in various bone densities. BMC Med Imaging. 2019;19(1):34.

11. Pero AC, Scavassin PM, Policastro VB, de Oliveira Júnior NM, Mendoza Marin DO, Silva M, et al. Masticatory function in complete denture wearers varying degree of mandibular bone resorption and occlusion concept: canineguided occlusion versus bilateral balanced occlusion in a cross-over trial. J Prosthodont Res. 2019;63(4):421-7.

12. Shala K, Tmava-Dragusha A, Dula L, Pustina-Krasniqi T, Bicaj T, Ahmedi E, et al. Evaluation of Maximum Bite Force in Patients with Complete Dentures. Open Access Maced J Med Sci. 2018;6(3):559-63.

13. Ren C, McGrath C, Yang Y. Edentulism and associated factors among community-dwelling middle-aged and elderly adults in China. Gerodontology. 2017;34(2):195-207.

14. Yamazaki T, Martiniuk AL, Irie K, Sokejima S, Lee CM. Does a mandibular overdenture improve nutrient intake and markers of nutritional status better than conventional complete denture? A systematic review and meta-analysis. BMJ Open. 2016;6(8):e011799.

15. Jacobs R, Salmon B, Codari M, Hassan B, Bornstein MM. Cone beam computed tomography in implant dentistry: recommendations for clinical use. BMC Oral Health. 2018;18(1):88

16. Lee E, Shin SY. The influence of the number and the type of magnetic attachment on the retention of mandibular mini implant overdenture. 2017;9(1):14-21

17. Das KP, Jahangiri L, Katz RV. The first-choice standard of care for an edentulous mandible: a Delphi method survey of academic prosthodontists in the United States. J Am Dent Assoc. 2012;143(8):881-9.

18. Jofre J, Cendoya P, Munoz P. Effect of splinting mini-implants on marginal bone loss: a biomechanical model and clinical randomized study with mandibular overdentures. Int J Oral Maxillofac Implants. 2010;25(6):1137-44.

19. Abbasi MRA, Vinnakota DN, Sankar V, Kamatham R. Comparison of stress induced in mandible around an implant-supported overdenture with locator attachment and telescopic crowns - a finite element analysis. Med Pharm Rep. 2020;93(2):181-9.

20. Maryod WH, Ali SM, Shawky AF. Immediate versus early loading of mini-implants supporting mandibular overdentures: a preliminary 3-year clinical outcome report. Int $\mathbf{J}$ Prosthodont. 2014;27(6):553-60.

21. Żmudzki J, Chladek G, Kasperski J. Biomechanical factors related to occlusal load transfer in removable complete dentures. Biomech Model Mechanobiol. 2015;14(4): 679-91.

22. Kuroshima S, Yasutake M, Tsuiki K, Nakano T, Sawase T. Structural and Qualitative Bone Remodeling Around Repetitive Loaded Implants in Rabbits. Clin Implant Dent Relat Res. 2015;17 Suppl 2:e699-710.

23. Tuzzolo Neto H, Tuzita AS, de Vasconcellos Moura R, Zaffalon Casati M, Gehrke SA, Mikail Melo Mesquita A. A Comparative Analysis of Implants Presenting Different Diameters: Extra-Narrow, Narrow and Conventional. Materials (Basel). 2020;13(8).

24. Sohrabi K, Mushantat A, Esfandiari S, Feine J. How successful are small-diameter implants? A literature review. Clin Oral Implants Res. 2012;23(5):515-25.

25. Payne AG, Alsabeeha NH, Atieh MA, Esposito M, Ma S, Anas El-Wegoud M. Interventions for replacing missing teeth: attachment systems for implant overdentures in edentulous jaws. Cochrane Database Syst Rev. 2018;10:CD008001. 
26. Keshk AM, Alqutaibi AY, Algabri RS, Swedan MS, Kaddah A. Prosthodontic maintenance and peri-implant tissue conditions for telescopic attachment-retained mandibular implant overdenture: Systematic review and meta-analysis of randomized clinical trials. Eur J Dent. 2017;11(4):559-68.

27. Elsyad MA, Khairallah AS. Chewing efficiency and maximum bite force with different attachment systems of implant overdentures: a crossover study. Clin Oral Implants Res. 2017;28(6):677-82.

28. Ohi T, Komiyama T, Miyoshi Y, Murakami T, Tsuboi A, Tomata Y, et al. Maximum Occlusal Force and Incident Functional Disability in Older Adults: The Tsurugaya Project. JDR Clin Trans Res. 2018;3(2):195-202. 